\title{
INFLUENCE OF PRINTING AND LOADING DIRECTION ON MECHANICAL RESPONSE IN 3D PRINTED MODELS OF HUMAN TRABECULAR BONE
}

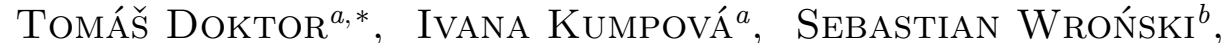 \\ MACIEJ Śniechowski ${ }^{b}$, JACEK TARASIUK $^{b}$, GiAnCARlo Forte $^{c}$, \\ DANIEL KYTÝr $\check{R}^{a}$
}

${ }^{a}$ Intitute of Theoretical and Applied Mechanics of the CAS, Prosecká 76, 19000 Prague 9, Czech republic

${ }^{b}$ AGH University of Science and Technology, aleja Adama Mickiewicza 30, 30-059 Kraków, Poland

c International Clinical Research Center of St. Anne's University Hospital Brno, Pekařská 53, 65691 Brno, Czech republic

* corresponding author: doktor@itam.cas.cz

\begin{abstract}
The paper deals with investigation on directional variations of mechanical response in 3D printed models of human trabecular bone. Sample of trabecular bone tissue was resected from human donor and 3D model was obtained by X-ray computed tomography. Then a series of cubical samples was prepared by additive manufacturing technique and tested by uniaxial compression loading mode. Mechanical response was compared in nine different combinations of direction of 3D printing and loading direction. The results show neglectible influence on the deformation response in elastic region (stiffness) and significant changes of the behaviour in plastic region (stress and strain at yield point, strain at full collapse).
\end{abstract}

KEYWORDS: additive manufacturing, tomography, deformation response.

\section{INTRODUCTION}

In the regenerative medicine bone scaffolds serve to support the bone healing process [1, 2]. Additive manufacturing provides possibilities for manufacturing of the scaffold structure with tailored properties. Moreover, mechanical response and topological properties of additively manufactured stuctures may be investigated and optimised using experimental modeling 3. 4. However, direction of the 3D printing related to the loading direction may influence the effective mechanical properties and therefore affect the reliability of such analyses. In order to investigate the influence of the printing direction a series of uniaxial loading tests was performed on additively manufactured models of the human trabecular bone.

\section{MATERIALS AND METHODS}

\subsection{SAMPLE PREPARATION}

Trabecular bone tissue was extracted from a cadaver human donor (male, 52 years, non pathological conditions). The extraction was performed using hollow drill using a low-speed drilling machine in direction coaxial with column femoris. Diameter and length of the resected sample were $18 \mathrm{~mm}$ and $40 \mathrm{~mm}$, respectively. The sample is depicted in Figure 1 The resected tissue was then cleaned in ultrasonic cleaner using detergent solution in order to remove bone marrow.

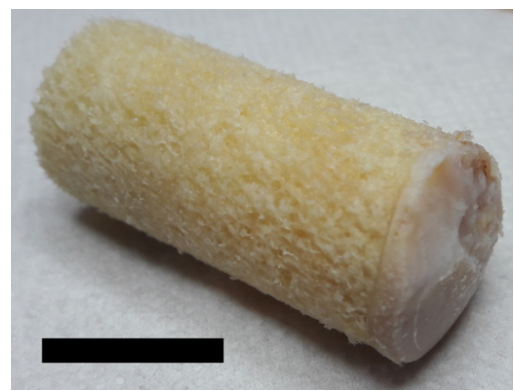

Figure 1. Trabecular bone sample resected from human caput femoris. Scale bar $20 \mathrm{~mm}$.

\subsection{TOMOGRAPHIC SCANNING AND RECONSTRUCTION}

The extracted sample was then tomographically scanned using TORATOM (unique patented tomographic facility placed in Centre of Excelence in Telc, ITAM, Czech republic) [5]. For the irradiation X-ray tube XWT 160 TCHR (X-Ray WorX, GmbH, Germany) was used with tube voltage $90 \mathrm{kV}$ and target current $76 \mu \mathrm{A}$. For the acquisition flat panel detector XRD 1622 AP 14 (Perkin Elmer, USA) was used. Resolution of the detector was $2048 \times 2048 \mathrm{px}$. The tomographic setup is depicted in Figure 2 To achieve sufficient magnification, the following geometry of the tomographic setup was used: focus-detector distance was $1200 \mathrm{~mm}$ and focus-sample distance was $60 \mathrm{~mm}$, which resulted in magnification $20 \times$. Duration time of the acquisition was $2000 \mathrm{~ms}$ per projection and resulting pixel size was $10 \mu \mathrm{m}$. 

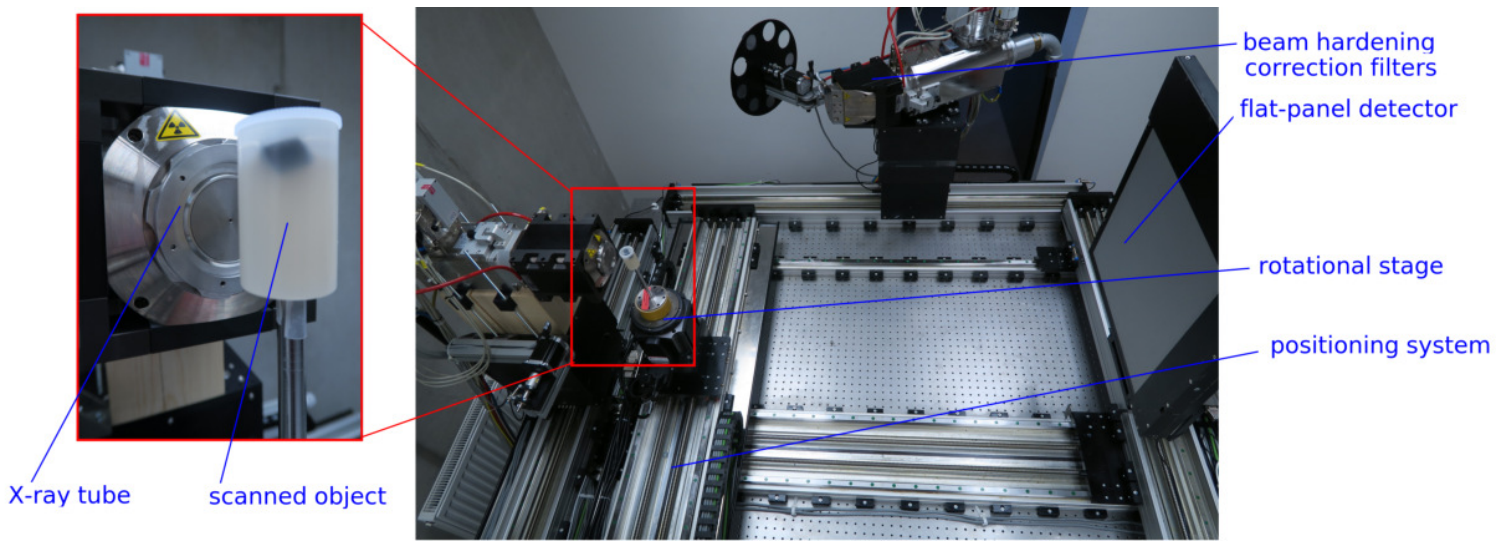

FiguRE 2. TORATOM scanning setup.

Acquired tomographic projections were then recontructed using VG Studio software tool (Volume Graphics, GmbH, Germany). From the reconstructed matrix a cubical region of interest (ROI) with size $1000 \times 1000 \times 1000 \mathrm{px}^{3}$ was selected for $3 \mathrm{D}$ print. Visualisation of the ROI is depicted in Figure 3

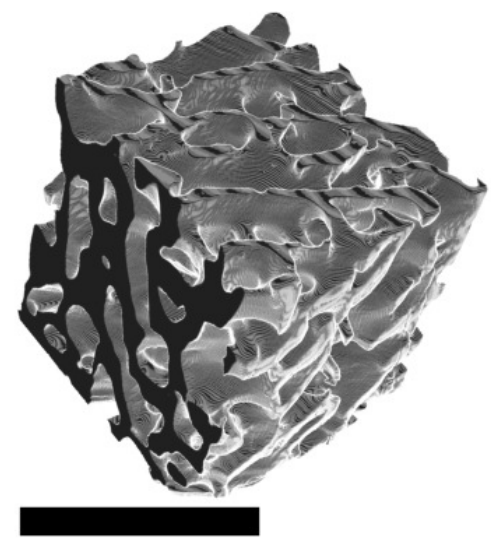

FiguRE 3. Selected region of interest in the reconstructed 3D matrix. Scale bar $10 \mathrm{~mm}$.

\subsection{Additive manufacturing}

Subsequently, nine samples were manufactured using $3 \mathrm{D}$ printer, three in each group printed along different axes. The samples were prepared at additive manufacturing facility placed at AGH University Krakow. Custom modified device B9creator (B9creations, LLC, USA) was used together with base material Vorex resin (Madesolid, USA) with adition of photoabsorber Sudan I (Sigma Aldrich, USA). Cubic samples with edge length $10 \mathrm{~mm}$ were prepared (depicted in Figure 4). Resolution in the printed plane corresponded to pixel size $30 \times 30 \mu \mathrm{m}$ and the layer thickness was $30 \mu \mathrm{m}$ as well. As typical thickness of human trabecula in the selected location varies in range 120 to $160 \mu \mathrm{m}$ [6] at least four voxels across the trabeculae thickness were present in the printed model. Hence the 3D printer resolution was sufficient to preserve all features of the trabecular structure without scaling of the model.

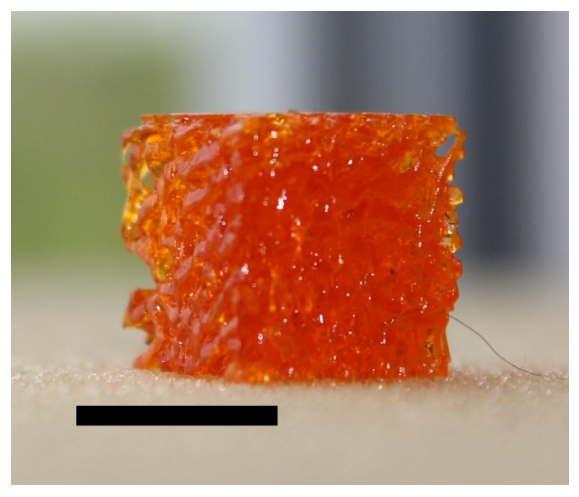

Figure 4. Additively manufactured trabecular bone structure. Scale bar $10 \mathrm{~mm}$.

\subsection{UNIAXIAL COMPRESSION TESTS}

The additively manufactured samples were then subjected to uniaxial compression using a custom loading frame [7. Loading capacity od the loading frame was $2 \mathrm{kN}$. Loading was provided by a stepper motor attached to a harmonic drive and controlled by an inhouse control software based on LinuxCNC interface [8. The setup was instrumented by force transducer (type U9b, HBM, Germany) with loading capacity $1 \mathrm{kN}$. The loading setup is depicted in Figure 5 .

Displacement controlled compression tests with loading rate $30 \mu \mathrm{m} \cdot \mathrm{s}^{-1}$ were performed. Final displacement corresponding to overall strain 0.55 was prescribed (entire available travel range of the loading frame was used to ensure description of both elastic region and plastic collapse of the cellular structure). However in several tests the loading was stopped at lower displacement due to the force drop which indicated complete failure of the structure.

\subsection{Strain measurement}

Loading scene was captured by monochromatic CCD camera AVT Manta G504B (Alied Vision GmbH, Germany) attached to a bi-telecentric lens TZCR072 (OptoEngineering, Italy) at resolution $2452 \times 2056 \mathrm{px}$ at $2 \mathrm{fps}$. For camera read out in-house acquisition software [9] based on OpenCV library [10] was used. 


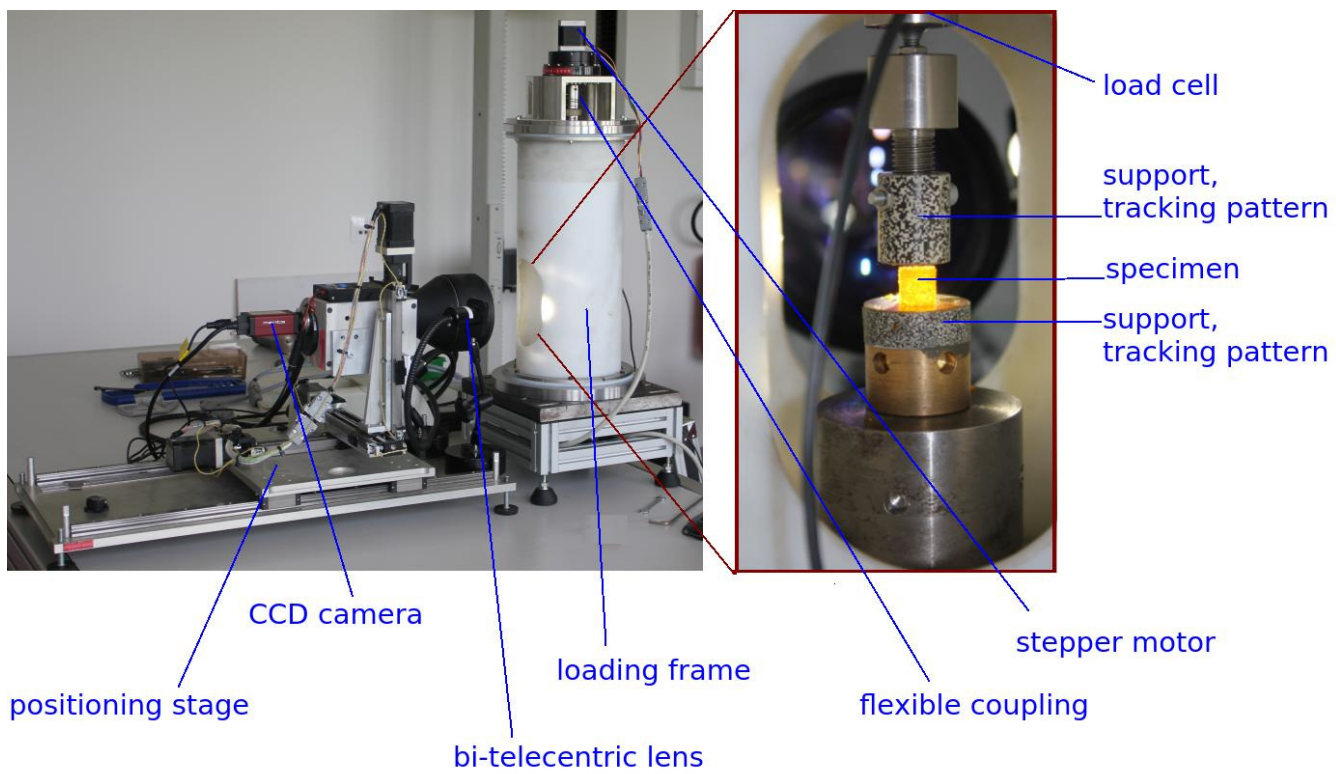

Figure 5. Custom loading setup for uniaxial compression tests.

Displacement of the loading supports was tracked by custom DIC software tool 11] based on Lucas-Kanade trancking algorithm [12.

The overall strain was measured optically based on projections of the loading scene using Digital Image Correlation algorithm (DIC). Due to the nearly transparent nature of base material of the samples the displacement tracking was not successfull at the specimens' surface and DIC was used for tracking of the loading supports only.

\section{Results}

From the calculated displacements and force records stress-strain diagrams were constructed and used for comparison among the tested groups. The obtained loading curves are depicted in Figures 6, 7 and 8 . where the samples were groupped with respect to the loading direction in order to provide comparison between different printing directions.

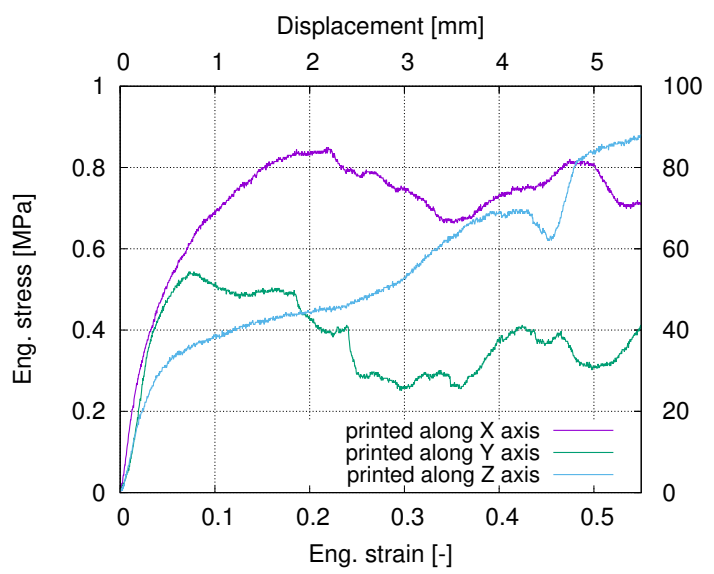

\begin{tabular}{l}
$z$ \\
\multirow{2}{0}{} \\
0 \\
0 \\
0 \\
$\frac{.}{0}$ \\
0 \\
0 \\
9
\end{tabular}

Figure 6. Loading curves of samples loaded along $\mathrm{X}$ direction.

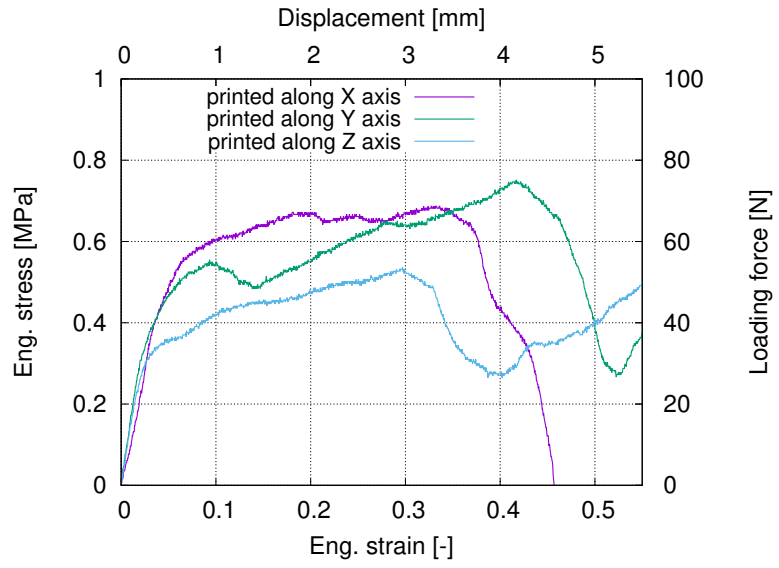

FiguRE 7. Loading curves of samples loaded along $\mathrm{Y}$ direction.

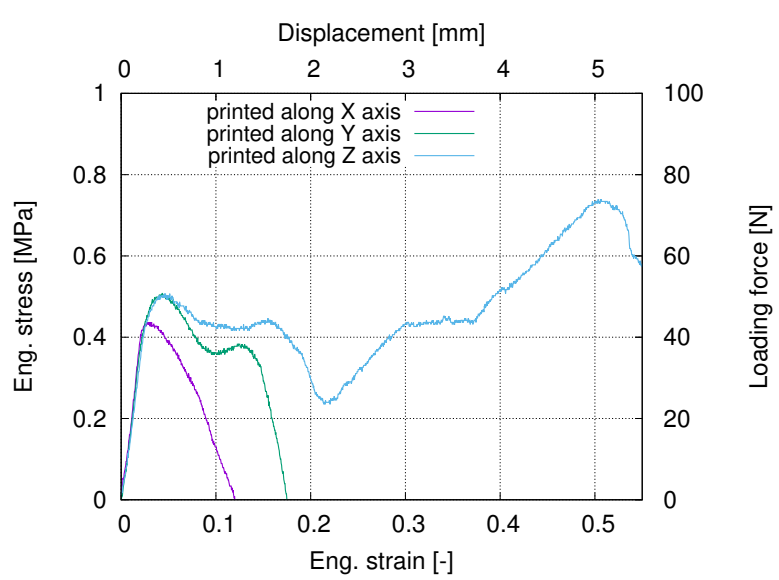

FiguRE 8. Loading curves of samples loaded along $\mathrm{Z}$ direction. 


\section{Conclusions}

Based on the uniaxial loading tests of different sets of $3 \mathrm{D}$ printed specimen of human trabecular bone influence of printing and loading direction on deformation behaviour was studied. Compared to previous studies on deformation response of trabecular tissue (human femur [13] or rat vertebra [14]) the additively manufactured models exhibit similar behaviour up to the first plastic collapse in terms of continuous linear elastic region with smooth yield region.

The mechanical response was compared in terms of effective Young's modulus, yield stress and strain and peak force at failure. Stress-strain diagrams of the 3D printed models of trabecular bone were consistent in the groups with each loading direction in terms of stiffness (slope of the linear response). Highest peak force was observed in samples loaded along the direction of 3D printing in all three groups. In several samples full collapse of the cellular structure occurred when the loading axis was perpendicular to the printing direction.

\section{ACKNOWLEDGEMENTS}

The research has been supported by the European Regional Development Fund in frame of the projects Kompetenzzentrum MechanoBiologie (ATCZ133) in the Interreg V-A Austria - Czech Republic programme and by the institutional support of RVO: 68378297. This work was partially supported by the Faculty of Physics and Applied Computer Science AGH UST statutory tasks within subsidy of Ministry of Science and Higher Education.

\section{REFERENCES}

[1] Y. Azizeh-Mitra, H. M. Enamul, P. R. G. S. V., U. Nicholas. Current strategies in multiphasic scaffold design for osteochondral tissue engineering: A review. Journal of Biomedical Materials Research Part A 103(7):2460-2481, 2015. DOI:10.1002/jbm.a.35356

[2] A. R. Vaccaro, K. Chiba, J. G. Heller, et al. Bone grafting alternatives in spinal surgery. The Spine Journal 2(3):206-215, 2002. DOI:https://doi.org/10.1016/S1529-9430(02)00180-8

[3] P. Koudelka, T. Doktor, D. Kytyr, et al. Micromechanical properties of biocompatible materials for bone tissue engineering produced by direct $3 \mathrm{~d}$ printing. Key Engineering Materials 662:138-141, 2015. DOI:10.4028/www.scientific.net/KEM.662.138
[4] D. Kytýřr, T. Doktor, O. Jiroušek, et al. Deformation behaviour of a natural-shaped bone scaffold. Materiali in Tehnologije 50(3):301-305, 2016. DOI:10.17222/mit.2014.190.

[5] I. Kumpova, D. Vavrik, T. Fila, et al. High resolution micro-ct of low attenuating organic materials using large area photon-counting detector. Journal of Instrumentation 11(2), 2016. DOI:10.1088/1748-0221/11/02/C02003.

[6] A. Nazarian, J. Muller, D. Zurakowski, et al. Densitometric, morphometric and mechanical distributions in the human proximal femur. Journal of Biomechanics 40(11):2573-2579, 2007. DOI:doi.org/10.1016/j.jbiomech.2006.11.022.

[7] P. Zlamal, O. Jirousek, D. Vavrik. A Novel Compression/tension Device for Investigation of Trabecular Bone Failure Using Real-time micro-CT

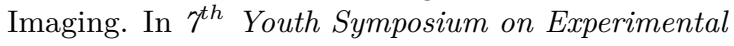
Solid Mechanics, pp. 91-91. 2008.

[8] V. Rada, T. Fila, P. Zlamal, et al. Multi-channel control system for in-situ laboratory loading devices. Acta Polytechnica CTU Proceedings 18:15-19 2018. DOI:10.14311/APP.2018.18.0015

[9] T. Doktor, D. Kytyr, P. Zlamal, et al. Simulation of a three-point bending test on the isolated cell wall of aluminium foam. Civil-Comp Proceedings 102, 2013.

[10] Bradski, Gary. The opencv library, 2000. http://www.drdobbs.com/open-source/ the-opencv-library/184404319.

[11] I. Jandejsek, J. Valach, D. Vavrik. Optimization and Calibration of Digital Image Correlation method. In Proceedings of the $48^{\text {th }}$ International Scientific Conference on Experimental Stress Analysis, pp. 121-126. 2010.

[12] B. D. Lucas, T. Kanade. Iterative image registration technique with an application to stereo vision. vol. 2, pp. 674-679. 1981

[13] P. Zlamal, O. Jirousek, T. Doktor, et al. Compressive behaviour of trabecular tissue: Finite element modelling and comparison using digital volume correlation. Civil-Comp Proceedings 102, 2013.

[14] T. Fila, D. Kytyr, P. Zlamal, et al. High-resolution time-lapse tomography of rat vertebrae during compressive loading: Deformation response analysis. Journal of Instrumentation 9(5), 2014. DOI:10.1088/1748-0221/9/05/C05054. 